\title{
Activar el poder de creación
}

"La ciencia es una empresa colectiva. La solución de un problema cientifico, para ser aceptada, debe satisfacer exigencias y criterios rigurosos. Sin embargo esos apremios no eliminan la creatividad: son su desafios".

Ilya Prigogine

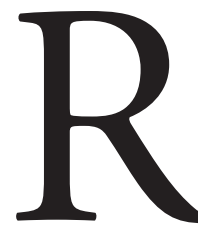

ecientemente ha tomado nuevo impulso el debate sobre el papel de la academia en la producción de conocimiento. Esto se da en un entorno en donde nuevos actores han tomado la delantera en la promoción de innovaciones tecnológicas y han venido copando campos que antes no se disputaban a las universidades y centros de investigación ligados a ellas.

Se está produciendo un desplazamiento de la gestión del conocimiento en esta nueva era del capitalismo cognitivo y la dirección señala hacia el surgimiento de nuevos territorios de la investigación, colonizados por el poder financiero de las grandes corporaciones trasnacionales. Parecen ser muy pocas las posibilidades de competir exitosamente con el tamaño de los recursos puestos a disposición de estos centros de poder económico y político, que canalizan con éxito el ingenio humano y lo convierten en rentables prodigios tecnológicos, con una enorme capacidad de subjetivación, amplificada mediáticamente, que multiplica las ganancias y genera nuevas exclusiones en la sociedad de consumo.

Sin embargo, como señala el laureado Nóbel de Química 1977, "Distinguimos nuevos horizontes, nuevas preguntas nuevos riesgos. Vivimos un momento privilegiado de la historia de la ciencia" (Prigogine, 2001: 219). Y esto se da no solo por la avalancha de nuevos productos tecnológicos disponibles en el mercado, que resultan de descubrimientos científicos patrocinados por el capital trasnacional, sino porque se han abierto rupturas epistémicas y discusiones sociales que hasta hace poco eran el objeto exclusivo de especialistas.

El debate se ha trasladado a la sociedad entera, ha roto no solo las fronteras de la academia, sino que empieza a transgredir las empaquetaduras comerciales y los intereses privados. Se ha creado un nuevo campo de lo público, trazado desde las esferas política, cultural y social, que interroga los procesos de producción social del conocimiento, sus métodos, sus usos, la apropiación privada de los beneficios. El problema es que si la ciencia y la tecnología se han transformado en la más poderosa fuerza productiva, con todas las implicaciones en el reordenamiento de las relaciones sociales y en las asimetrías del poder, eso quiere decir que también se ha redimensionado su lugar como una fuerza social. Por lo tanto, un mínimo de coherencia exigiría estar debatiendo no solamente la dimensión técnico-económica del asunto, sino profundizando en el significado de nuevos conceptos como el de innovación social, que pretenden erigir puentes entre el desarrollo tecnológico y la adecuación de las condiciones de estructura social e infraestructura institucional.

Para Colombia este problema cobra hoy una importancia definitiva. Acudimos al cierre de una etapa marcada por la polarización ideológica en la que, desde el poder del Estado, se pretendió que el desarrollo dependía de una variable esencial: la seguridad. Seguridad para garantizar la inversión extranjera; seguridad para favorecer la expansión de los mercados y mantener altas tasas de rentabilidad de los capitales privados. Este énfasis que, aunque discutible, no es ilegítimo como opción de un sector de la sociedad, tuvo como fundamento una lógica de guerra enquistada, que amplió las repercusiones nefastas sobre importantes grupos humanos del campo y de las ciudades, que vieron incrementar los crímenes de lesa humanidad, el desplazamiento forzado y la pobreza. Mientras tanto, áreas estratégicas para la vida del país como 
la producción de alimentos, el sistema de salud, la infraestructura vial y la protección del medio ambiente se mantuvieron en el descuido o entraron en situación de profunda crisis.

La investigación científica y, en general, la producción de conocimiento, entró en ese rango de los procesos que, siendo fundamentales, se mantuvieron en la penumbra y el desaliento. Durante este período que abarca por lo menos la última década, la inversión en el sistema nacional de investigaciones se mantuvo en vergonzosos rangos inferiores al 3\% del PIB, muy por debajo del esfuerzo de países vecinos como Brasil.

La cuestión, sin embargo, no se remite exclusivamente al incumplimiento de los deberes estatales o de las empresas en este campo. Para los académicos cabe también una reflexión autocrítica en torno al papel jugado por los centros universitarios y, más concretamente en su aporte a la producción de conocimientos pertinentes y relevantes para la transformación del mundo. Eso implica una reflexión sobre la manera como se abordan los saberes y las formas de conocimiento social que se incuban en las comunidades, el tipo de sistematización y diálogo que se establece con ellos, sus procesos de legitimación y la indagación por el poder que adquieren determinados tipos de producción científica, que tienden a excluir los saberes ancestrales y populares minimizando su capacidad de afectación sobre el conjunto del entorno social y su fuerza de transformación.

Si algún sentido puede haber en el concepto de innovación social puede estar en la construcción de desplazamientos teóricos y metodológicos que retornen la mirada al inconmensurable poder de creación de la sociedad y que intenten superar la hegemonía absoluta de la racionalidad del mercado y de la guerra, que no solo se ha trasladado a diversas formas de la vida pública, sino que se ha transformado en un dispositivo de producción de subjetividades y de relaciones sociales que permean la vida cotidiana y los procesos de construcción de conocimiento y de verdad. El núcleo duro de esta transformación radica en explicar las intrincadas redes de la vida a partir de un mundo pleno de diversidad, evitando caer en la simplificación de un permanente cuadro constituido por dos opuestos que se repelen y de cuya lucha incesante habrá de surgir lo nuevo. Sólo la diferencia puede ser formadora, impulsora y productora de encuentros profundos; comprender su dinámica y su riqueza es el camino para crear nuevas formas de pensar, nuevas maneras de existir.

La desvalorización de la diferencia contribuye a opacar los significados más profundos del vínculo social; sólo en medio de la multiplicidad es posible percibir el contenido vital ontológico de la fraternidad y la convivencia humanas, así como todos aquellos valores sobre los cuales está constituida la potencia de ser de las sociedades, que se reeditan a diario no a pesar, sino impulsados por el motor de la eclosión de los modos de ser singulares que buscan conectividades que hagan posible afirmar la vida. En medio de estos debates propositivos arribamos a la décima edición de POLISEMIA.

En la sección Pensamiento Social Ela Isabel Téllez, investigadora del Grupo Crisálida de UNIMINUTO, presenta su artículo: El sentido del tejido social en la construcción de comunidad, adentrándose en la discusión sobre las características que configuran el entramado social y la compleja definición de la categoría "comunidad", a partir de una larga experiencia de trabajo comunitario.

La sección habitual Reflexiones Filosóficas acoge en esta edición tres artículos.

Diversidad y cohesión: arte, ecosistemas, sociedades del abogado y ex Ministro de Educación Germán Bula.

Nuestro permanente colaborador Jorge Vergara Estévez, filósofo chileno, vinculado al Grupo de Investigación Ciudadanía, Paz y Desarrollo de UNIMINUTO, ahonda en La crítica de las ciencias y de la modernidad.

Diego Fernando Silva Prada, filósofo de profesión y quien se desempeña como investigador del CEIHS presenta su texto: Más allá de la concepción coactiva del poder. Los aportes de Hannah Arendt y Norbert Elias a la teoria politica, que sintetiza la crítica al concepto y las prácticas del 
poder dominantes, desde la perspectiva de estos dos filósofos políticos contemporáneos que tanta influencia han tenido en el mundo intelectual de occidente.

La sección Caminos de Paz y Noviolencia publica el artículo: La Noviolencia y nuevas claves para leer a Jesús del politólogo Carlos Eduardo Martínez, director de la Escuela de Paz y Desarrollo de UNIMINUTO e investigador del Grupo "Ciudadanía, Paz y Desarrollo”.

Se cierra esta edición con la reseña de dos libros recientemente publicados por la Facultad de Ciencias Humanas y Sociales de la Universidad: Navegar en la incertidumbre el desafío de seguir siendo humano en un mundo sin certezas del sociólogo chileno Antonio Elizalde y Política sin Violencia del historiador español Mario López Martínez. Las reseńas fueron elaboradas por Oscar Useche y Rocío Martínez respectivamente. 